\title{
EDITORIALS
}

\section{The ACGME's 2011 Changes to Resident Duty Hours: Are They an Unfunded Mandate on Teaching Hospitals?}

\author{
Patrick S. Romano, MD MPH ${ }^{7}$ and Kevin Volpp, MD, $P h D^{2}$ \\ 'UC Davis Division of General Medicine and Center for Healthcare Policy and Research, Sacramento, CA, USA; ${ }^{2}$ Philadelphia Veterans Affairs \\ Medical Center, Leonard Davis Institute Center for Health Incentives and Behavioral Economics, University of Pennsylvania, Philadelphia, PA, USA.
}

J Gen Intern Med 27(2):136-8

DOI: $10.1007 / \mathrm{s} 11606-011-1936-\mathrm{x}$

(C) Society of General Internal Medicine 2011

$\mathrm{T}$ hroughout America, teaching hospitals are struggling to meet the Accreditation Council for Graduate Medical Education's (ACGME) new resident duty-hour standards. Effective July 2011, the Common Program Requirements state that duty hours must be limited to 80 hours per week, averaged over a four-week period, including in-house call and moonlighting (although exceptions may be granted up to 88 hours "based on a sound educational rationale"). Residents must be scheduled for at least one duty-free day (without athome call) every week, averaged over four weeks. Duty periods of interns must not exceed 16 hours. Upper level residents may be scheduled up to 24 hours of continuous duty, with up to four additional hours for transitions in care, but "strategic napping... is strongly suggested." PGY-1 and intermediatelevel residents must have eight duty-free hours between scheduled duty periods, and 14 duty-free hours after 24 hours of in-house duty. Residents must not be scheduled for more than six consecutive nights of night float, and higher level residents must be scheduled for in-house call no more frequently than every third night (averaged over four weeks). Finally, the ACGME mandated changes to the training environment to improve residents' educational experience and to mitigate potential adverse effects of the duty-hour restrictions. ${ }^{1}$

To inform the evolution of these requirements, Fletcher and colleagues conducted a systematic review to investigate the effect of the 2003 resident duty-hour rules on resident education, well-being, and patient care. Twenty studies assessed changes in mortality among medical and/or surgical patients $;^{2}$ most showed no effect after accounting for secular trends, but several showed improved mortality for patients with four medical conditions at Veterans Affairs hospitals, ${ }^{3}$ medical patients with infectious diseases or heart failure, ${ }^{4}$ and trauma patients. ${ }^{5}$ The 24 studies assessing complications had mixed results, but "the preponderance of studies demonstrated that some outcomes improved, some worsened, and some were unchanged." ${ }^{2}$ Several studies of resident education reported decreased operative experience among surgical residents after 2003, but resident burnout appears to have improved. In summary, these findings and those of another systematic review ${ }^{6}$ suggest that the 2003 rules did not have a meaningful effect, either favorable or unfavorable, on patient

Published online November 30, 2011 safety and quality-related outcomes. Of course, this conclusion begs many questions, including whether the 2003 rules showed little impact on patient outcomes because they were too strict (causing handoff-related harms that canceled out any benefit), because they were too lax (allowing fatigued residents to continue harming patients), or because patient outcomes are inherently insensitive to duty-hour regulation (given reasonable safeguards and redundancies provided by nurses, other trainees, and faculty). If modest reductions in resident work hours had no impact, then would further reductions also have no impact-because there is no true association between resident fatigue and patient outcomes-or would they have more impact-because resident fatigue may then fall below a hypothetical patient safety threshold?

With this historical background, Nuckols and Escarce attempted to estimate the direct costs (across all US hospitals) associated with different strategies for implementing the 2011 ACGME requirements, the net costs to major teaching hospitals, and the cost-effectiveness to society, accounting for potential effects of reduced duty hours on preventable adverse events. ${ }^{7}$ This is an extraordinarily challenging but important task. Skeptics have argued that the ACGME requirements will compromise residents' continuity of care and development of core competencies, ${ }^{8}$ while imposing a substantial unfunded mandate with little direct evidence that quality will improve. However, the size of this economic burden must be better understood. If the burden is substantial, then a variety of adverse consequences should be anticipated. For example, teaching hospitals might mitigate this burden by reducing expenditures in ways that might compromise patient outcomes (e.g., by deferring capital expenditures or eliminating staff positions). Teaching hospitals that do not have a core mission of teaching may respond by eliminating residency programs or de-affiliating with residency programs in their communities. Or they may increase training positions in specialties in which work hours are not an issue (e.g., dermatology, emergency medicine) while reducing training positions in specialties such as internal medicine and general surgery. Increased physician labor costs may also force teaching hospitals to raise prices for commercial patients, weakening their competitiveness in local markets. Medicare's formula for direct graduate medical education (DGME) payments precludes teaching hospitals from passing on ACGME-related costs to the Centers for Medicare \& Medicaid Services because the per-resident amount is based on costs incurred in a base year period (1984 or 1985), updated annually for inflation. ${ }^{9}$ The National Commission on Fiscal Responsibility and Reform ("Bowles-Simpson") and other deficit reduction plans would reduce DGME payments; ${ }^{10}$ any adjustment to cover ACGME-related costs would be a "tough sell" in the current environment. 
Building on a previous economic evaluation of the Institute of Medicine's recommendations on resident duty hours, ${ }^{11}$ Nuckols and Escarce report that duty-hour changes will cost $\$ 177$ million annually if interns maintain current productivity, or up to $\$ 982$ million annually if they transfer excess work to a mixture of substitutes. Mandatory changes in the training environment are estimated to cost an additional \$191 million annually. Curiously, a different analytic approach using Monte Carlo simulation generated a higher estimate of total direct annual costs, \$1,424 million (95\% confidence interval, \$1,052-1,910 million), under the mixed-substitute assumption. Most importantly, Nuckols and Escarce report that a $1.9 \%$ to $6.8 \%$ reduction in preventable adverse events (PAEs) could make the ACGME policies cost-saving for society, but readily acknowledge that it is unknown whether any reduction will occur. How should we interpret these estimates? What do they mean for teaching hospitals and for society?

The critical challenge is that an economic analysis of this type is only as good as the data that go into it, and as defensible as the assumptions upon which it is based. While Nuckols and Escarce made reasonable assumptions, searched for the best cost estimates, and performed appropriate sensitivity analyses, it is easy to challenge specific choices. For example, they assumed that faculty physicians substituting for residents are twice as efficient, earn $\$ 76.46$ per hour $(2008$ dollars), and delegate tasks to licensed vocational nurses earning \$19.04 per hour. An equally plausible scenario is that these physicians are only $50 \%$ more efficient, earn $\$ 89.17$ per hour (based on average 2008 compensation for hospitalists ${ }^{12}$ ), and delegate tasks to registered nurses earning \$31.54 per hour. ${ }^{13}$ This alternative scenario could nearly double their estimate of labor substitution costs (Table 2, Scenario Y).

More importantly, we have very little data to inform the central question of whether the 2011 requirements will affect the risk of PAEs. The hypothesis that this risk will decrease is essentially based on one randomized controlled trial showing less fatigue ${ }^{14}$ and fewer "serious medical errors" ${ }^{15}$ when interns worked 16-hour shifts instead of overnight shifts in intensive care units, supported by laboratory-based studies and pre-post studies of medication errors. ${ }^{16}$ These findings may not generalize to other settings because the known hazards of care transitions ${ }^{17}$ were mitigated by a nurse-topatient ratio of $1: 1$ or $1: 2$, because the study was underpowered to compare PAE rates, and because the intervention was discontinued when the study ended, suggesting that 16-hour shifts were not universally embraced. ${ }^{18}$ As Nuckols and Escarce posit, the relative risk of PAEs under the 2011 policies, compared with previous policies, could plausibly range from 0.9 to 1.1 , with profoundly variant estimates of resulting net costs, benefits, and cost-effectiveness.

Useful economic analyses of health care interventions invariably describe the robustness of their cost-effectiveness estimates, given plausible variation in underlying assumptions, and highlight the parameters that have the most impact on these estimates. Nuckols and Escarce's analysis of the ACGE requirements is an unusual example, in that the intervention may be regarded as reasonably cost-effective or extremely wasteful, depending on two essentially unknown factors: how teaching hospitals will "offload" excess resident work, and how shorter shifts for interns will affect PAE rates. Until these two phenomena are better understood, we are in uncharted territory and can only speculate-albeit in a somewhat informed manner, thanks to Nuckols and Escarce-about the economic impact. Research is also needed to address the effects of 16-hour shifts (versus "strategic napping") on transitions in care, resident learning and clinical experience, and physician professionalism.

The critical challenge for teaching hospitals, and for an entire nation that depends on the care and education that teaching hospitals provide, is to implement the ACGME requirements with as little additional faculty labor as possible (to minimize costs) and with rigorous safeguards to ensure that the expected reduction in fatigue-related errors translates into better patient outcomes (to maximize benefits), avoiding the countervailing risk of more frequent handoffs. If residency training directors and academic medical center leaders can accomplish this feat, while preserving the ethos of care delivery, then we may look back on 2011 as a year of upheaval in which postgraduate medical training nonetheless became safer, more humane, more educational, and perhaps even more cost-effective.

Corresponding Author: Patrick S. Romano, MD MPH; UC Davis Division of General Medicine and Center for Healthcare Policy and Research, 4150V Street, PSSB Suite 2400, Sacramento, CA 95817, USA (e-mail: psromano@ucdavis.edu).

\section{REFERENCES}

1. Common Program Requirements. Available at: http://www.acgme.org/ acWebsite/home/Common_Program_Requirements_07012011.pdf . Accessed October 31, 2011.

2. Fletcher KE, Reed DA, Arora VM. Patient safety, resident education and resident well-being following implementation of the 2003 ACGME duty hour rules. J Gen Intern Med. 2011;26:907-19.

3. Volpp KG, Rosen AK, Rosenbaum PR, et al. Mortality among patients in VA hospitals in the first 2 years following ACGME resident duty hour reform. JAMA. 2007;298:984-92.

4. Shetty KD, Bhattacharya J. Changes in hospital mortality associated with residency work-hour regulations. Ann Intern Med. 2007;147:7380.

5. Morrison CA, Wyatt MM, Carrick MM. Impact of the 80-hour work week on mortality and morbidity in trauma patients: an analysis of the National Trauma Data Bank. J Surg Res. 2009;154:157-62.

6. Moonesinghe SR, Lowery J, Shahi N, Millen A, Beard JD. Impact of reduction in working hours for doctors in training on postgraduate medical education and patients' outcomes: systematic review. BMJ. 2011;342:d1580.

7. Nuckols TK, Escarce JJ. Cost implications of ACGME's 2011 changes to resident duty hours and the training environment. J Gen Intern Med. 2012 doi:10.1007/S11606-011-1775-9.

8. Antiel RM, Thompson SM, Hafferty FW, et al. Duty hour recommendations and implications for meeting the ACGME core competencies: views of residency directors. Mayo Clin Proc. 2011;86:185-91.

9. Direct Graduate Medical Education. Available at: https://www.cms.gov/ AcuteinpatientPPS/06_dgme.asp . Accessed October 31, 2011.

10. Comparison of Medicare Provisions in Deficit and Debt Reduction Proposals. Available at: http://www.kff.org/medicare/8124.cfm. Accessed October 31, 2011.

11. Nuckols TK, Bhattacharya J, Wolman DM, Ulmer C, Escarce JJ. Cost implications of reduced work hours and workloads for resident physicians. N Engl J Med. 2009;360:2202-15.

12. American Medical Group Association Compensation Survey Data 2008 Report. Available at: https://www.cms.gov/AcuteInpatientPPS/ Downloads/AMGA_08_data.pdf. Accessed October 31, 2011.

13. National Compensation Survey: Occupational Earnings in the United States, 2008. Table 3. Available at: http://www.bls.gov/ncs/ncswage2008. htm\#Wage_Tables . Accessed October 31, 2011.

14. Lockley SW, Cronin JW, Evans EE, et al. Effect of reducing interns' weekly work hours on sleep and attentional failures. N Engl J Med. 2004;351:1829-37. 
15. Landrigan CP, Rothschild JM, Cronin JW, et al. Effect of reducing interns' work hours on serious medical errors in intensive care units. N Engl J Med. 2004;351:1838-48.

16. Reed DA, Fletcher KE, Arora VM. Systematic review: association of shift length, protected sleep time, and night float with patient care, residents' health, and education. Ann Intern Med. 2010;153:829-42.
17. Petersen LA, Brennan TA, O'Neil AC, Cook EF, Lee TH. Does housestaff discontinuity of care increase the risk for preventable adverse events? Ann Intern Med. 1994;121:866-72.

18. Volpp KG, Friedman W, Romano PS, Rosen A, Silber JH. Residency training at a crossroads: duty-hour standards 2010. Ann Intern Med. 2010;153:826-8. 